\title{
In Vivo Mechanical Loading Modulates Insulin-Like Growth Factor Binding Protein-2 Gene Expression in Rat Osteocytes
}

\author{
C. M. A. Reijnders, ${ }^{1}$ N. Bravenboer, ${ }^{1,2}$ P. J. Holzmann, ${ }^{1}$ F. Bhoelan, ${ }^{1}$ M. A. Blankenstein, ${ }^{2}$ P. Lips ${ }^{1}$ \\ ${ }^{1}$ Department of Endocrinology, Vrye Universiteit University Medical Center, PO Box 7057, 1007 MB Amsterdam, The Netherlands \\ ${ }^{2}$ Department of Clinical Chemistry, Vrye Universiteit University Medical Center, PO Box 7057, 1007 MB Amsterdam, The Netherlands
}

Received: 18 March 2006 / Accepted: 20 October 2006 / Online publication: 3 February 2007

\begin{abstract}
Mechanical stimulation is essential for maintaining skeletal integrity. Mechanosensitive osteocytes are important during the osteogenic response. The growth hormone-insulin-like growth factor (GH-IGF) axis plays a key role during regulation of bone formation and remodeling. Insulin-like growth factor binding proteins (IGFBPs) are able to modulate IGF activity. The aim of this study was to characterize the role of IGFBP-2 in the translation of mechanical stimuli into bone formation locally in rat tibiae. Female Wistar rats were assigned to three groups $(n=5)$ : load, sham, and control. The four-point bending model was used to induce a single period of mechanical loading on the tibial shaft. The effect on IGFBP-2 mRNA expression 6 hours after stimulation was determined with nonradioactive in situ hybridization on decalcified tibial sections. Endogenous IGFBP-2 mRNA was expressed in trabecular and cortical osteoblasts, some trabecular and subendocortical osteocytes, intracortical endothelial cells of blood vessels, and periosteum. Megakaryocytes, macrophages, and myeloid cells also expressed IGFBP-2 mRNA. Loading and sham loading did not affect IGFBP-2 mRNA expression in osteoblasts, bone marrow cells, and chondrocytes. An increase of IGFBP-2 mRNApositive osteocytes was shown in loaded (1.68-fold) and sham-loaded (1.35-fold) endocortical tibial shaft. In conclusion, 6 hours after a single loading session, the number of IGFBP-2 mRNA-expressing osteocytes at the endosteal side of the shaft and inner lamellae was increased in squeezed and bended tibiae. Mechanical stimulation modulates IGFBP-2 mRNA expression in endocortical osteocytes. We suggest that IGFBP-2 plays a role in the lamellar bone formation process.
\end{abstract}

Key words: Mechanical loading - Four-point bending system - Nonradioactive in situ hybridization IGFBP-2 mRNA expression - In vivo

Mechanical stimulation is important for the maintenance of the skeleton of humans and other animals [1-9]. Bone serves as a structural support for the body

Correspondence to: N. Bravenboer; E-mail: n.bravenboer@ vumc.nl and has the ability to modify its architecture throughout life. Mechanical stimulation regulates bone mass and architecture according to Frost's mechanostat hypothesis. Physical activity results in increased bone formation and decreased bone resorption, whereas inactivity has the opposite effect $[10,11]$.

The growth hormone-insulin-like growth factor $(\mathrm{GH}-$ IGF) axis plays an important role in the regulation of bone remodeling. Of the insulin-like growth factors (IGFs), IGF-I is predominantly expressed in rat bone and IGF-II is predominantly expressed in human bone [12-14]. IGFs are involved in bone formation after mechanical stimulation. Mechanical loading upregulates IGF-I mRNA expression in osteocytes, as shown in rat vertebra by Lean and colleagues using the caudal vertebra compression model [15]. Northern blot analysis also showed enhanced periosteal IGF-I mRNA expression after mechanical stimulation [16]. Besides an increase in IGF-I mRNA synthesis, Bravenboer and colleagues reported upregulation of IGF-I protein concentration in bone after mechanical stimulation using additional weight bearing in running rats (rat-withbackpack) [17].

As in other tissues, the autocrine and paracrine actions of IGFs in bone are modulated by a family of six structurally related binding proteins, the IGF binding proteins (IGFBPs). IGFBPs can be synthesized by osteoblasts $[18,19]$ and are capable of modulating the effects of IGFs by potentiating or inhibiting their action; some IGFBPs also have IGF-independent actions that can either inhibit or stimulate cellular function.

Since rat osteoblasts do not express IGFBP-1 [18, 20,21 , it is most likely that IGFBP-1 does not play a significant role during bone formation after mechanical stimulation in rats. Although IGFBP-2 is the major IGFBP synthesized by rat osteoblastic cells [18], a role for IGFBP-2 during mechanical loading has not been established yet. IGFBP-3 has both inhibitory and stimulatory effects on bone cells. IGFBP-4, which is locally produced by osteoblasts, has an inhibitory ef- 
fect on bone metabolism, whereas locally synthesized IGFBP-5 by osteoblasts has a stimulatory effect [18, 22, 23]. However, the effects of IGFBP-4 on osteoblasts are IGF-I-dependent, whereas IGFBP-5 probably acts as a store for IGFs in bone tissue [18, 22, 23]. IGFBP-6 is expressed in rat osteoblasts [24]. In conclusion, IGFBP-2 is the most abundant IGFBP in rat osteoblasts; however, the role of IGFBP-2 during bone formation after mechanical stimulation in vivo has not been determined yet. We hypothesized that IGFBP-2 mRNA expression level might be changed in bone cells during bone formation after mechanical stimulation.

The aim of this study, therefore, was to determine the localization of IGFBP-2 mRNA in the cortical tibial shaft after mechanical stimulation. To this end, we induced a single period of mechanical loading using the four-point bending model of Forwood and Turner [1, 2, 7]. This resulted in bone formation in the rat tibia 5-8 days after stimulation [25]. We developed an in situ hybridization method especially for bone tissue to detect the local osteogenic response at the cellular level 6 hours after a single period of dynamic loading.

\section{Materials and Methods}

\section{Animals}

Fifteen female 12-week-old Wistar rats $(235 \pm 12 \mathrm{~g}$; Harlan, Zeist, The Netherlands) were randomly assigned to three weight-matched groups ( $n=5$ /group): load, sham, and control. The animal experiment was in accordance with the governmental guidelines for the care and use of laboratory animals and approved by the Institutional Animal Care and Use Committee of the VU University Medical Center (Amsterdam, The Netherlands).

\section{In vivo Mechanical Loading}

The right tibiae underwent "mediolateral" loading (load), sham loading (sham, in which the opposed pads were placed at the inner position, $11 \mathrm{~mm}$ apart), or no loading (control) using the four-point bending system of Forwood and Turner $[1,7]$. Since loading will result in bending and squeezing of the tibia and sham loading only in squeezing of the tibia, the sham group was used as a control for the load group. The left tibiae served as contralateral controls. The four-point bending model [25] was used to generate a single period of dynamic loading of the right tibia in rats in vivo in order to detect acute changes of IGFBP-2 mRNA locally in bone tissue after stimulation by mechanical stress. The rats were subjected to a single episode of loading comprising 300 cycles $(2 \mathrm{~Hz})$ using a peak magnitude of $60 \mathrm{~N}$. Forwood and Turner showed that a single loading session resulted in bone formation in the rat tibia 5-8 days after stimulation [25]. Characterization of the in vivo strain using the four-point bending system was reported by Akhter and colleagues [26]. Using the four-point bending system at our laboratory, we demonstrated bone formation at the endosteal surface of the rat tibia 15 days after a single loading session with a frequency of $2 \mathrm{~Hz}$ during 300 cycles and an applied peak magnitude of $60 \mathrm{~N}$ [27]. The loading experiment was performed under general anesthesia $\left(2 \%\right.$ isoflurane in $1 \mathrm{~L} / \mathrm{min} \mathrm{O}_{2}$ and $2 \mathrm{~L} / \mathrm{min} \mathrm{N}_{2} \mathrm{O}$ ). The rats were killed exactly 6 hours after loading. This time point was based on the literature [15], which was confirmed by a time-course pilot experiment at our laboratory using real-time reverse-transcription polymerase chain reaction analysis $(\mathrm{H}$. W. van Essen, personal communication) showing the highest IGF-I mRNA expression 6 hours after loading. Since the actions of IGFs are influenced by their IGFBPs, we examined IGFBP-2 mRNA expression at 6 hours after loading. The tibiae were dissected and immediately fixed in $4 \%(\mathrm{w} / \mathrm{v})$ paraformaldehyde (buffered in phosphate-buffered saline [PBS], $\mathrm{pH} 7.4$ ) at $4^{\circ} \mathrm{C}$ for 24 hours.

\section{Tissue}

After fixation, the tibiae were decalcified in $10 \%$ ethylenediaminetetraacetic acid (EDTA) with $0.5 \%$ paraformaldehyde in PBS at $4^{\circ} \mathrm{C}$ for 4.5 weeks. Finally, the tibiae were washed in PBS and dehydrated through a series of ethanol and xylene at room temperature and embedded in paraffin.

As a positive control, brain tissue was used [28]. Brains were dissected rostrally to the cerebellum (interaural coordinate $0 \mathrm{~mm}$ ) and the hippocampus (interaural coordinate $4 \mathrm{~mm}$ ) in three coronal blocks and immediately fixed in $4 \%(\mathrm{w} / \mathrm{v})$ paraformaldehyde (buffered in PBS, $\mathrm{pH} 7.4$ ) at $4^{\circ} \mathrm{C}$ for 24 hours, followed by washing in PBS, dehydration through a series of ethanol and xylene at room temperature, and embedding in paraffin.

\section{Reagents}

All restriction enzymes and modifying enzymes were purchased from Roche Molecular Biochemicals (Mannheim, Germany), as well as digoxigenin-uridine triphosphate (UTP), antidigoxigenin Fab fragments, nitroblue tetrazolium chloride (NBT), 5-bromo-4-chloro-3-indolyl phosphate (BCIP), and blocking reagent. Nylon membranes were purchased from Qiagen (Hilden, Germany). Polyvinyl alcohol was obtained from Aldrich (Milwaukee, WI). Euparal mounting medium was purchased from Chroma Gesellschaft (Waldeck, Division Chroma, Münster, Germany). Silanecoated glass slides were obtained from Sigma-Aldrich (St. Louis, MO).

Mouse IGFBP-2 cDNA was kindly provided by Dr. S. L. S. Drop and Dr. J. W. van Neck (Department of Pediatrics, Sophia Children's Hospital, Erasmus University, Rotterdam, The Netherlands) via Dr. S. C. van Buul-Offers (Department of Metabolic and Endocrine Diseases, University Medical Center, Utrecht, The Netherlands).

\section{Synthesis of Digoxigenin-Labeled Complementary RNA (cRNA) Probes}

Standard in vitro transcription reactions were carried out using T7- and Sp6-RNA polymerase with digoxigenin-UTP as a substrate [29]. cDNA encoding mouse IGFBP-2 cDNA, corresponding to amino acid position $98-258$ and showing $95 \%$ homology with the corresponding rat IGFBP-2 cDNA fragment, was used as a template for the synthesis of antisense and sense digoxigenin-labeled RNA probe. The probe was specific for the mRNAs analyzed. The IGBP-2 probe did not show cross-reactivity with different types of mouse tissues (spleen, thymus, and brain) $[28,30,31]$.

\section{Nonradioactive In Situ Hybridization}

Serial, longitudinal tibial sections $(5 \mu \mathrm{m})$, which were cut in the posterior-anterior direction, and cross-sectional control brain sections $(5 \mu \mathrm{m})$ were mounted onto RNase-free silane-coated glass slides and dried at $56^{\circ} \mathrm{C}$ for at least 3 days. Corresponding sections of the right and left tibia of one rat were mounted on the same glass slide. In situ hybridization was 
performed on every fiftieth section with a total of five slides per tibia (i.e., sections I, II, II, IV, and V). All sections were dewaxed, rehydrated, and rinsed in water. The sections were pretreated with $0.2 \mathrm{~N} \mathrm{HCl}$ for 15 minutes at room temperature, permeabilized in proteinase $\mathrm{K}(15 \mu \mathrm{g} / \mathrm{mL})$ for 30 minutes at $37^{\circ} \mathrm{C}$, and subjected to an acetylation treatment [32]. Sections were rinsed in $2 \times \mathrm{SSC}(0.3 \mathrm{M}$ sodium chloride and 0.03 $M$ sodium citrate) and kept in this solution until the start of hybridization.

Hybridization was performed in a solution containing $50 \%$ formamide, $2 \times \mathrm{SSC}$, $1 \times$ Denhardt's solution, $250 \mu \mathrm{g} / \mathrm{mL}$ transfer RNA, $480 \mu \mathrm{g} / \mathrm{mL}$ herring sperm RNA, $10 \%$ dextransulfate, and the mouse IGFBP-2 digoxigenin-labeled cRNA probe at concentrations of $500 \mathrm{pg} / \mu \mathrm{L}$ (brain) and $1,000 \mathrm{pg} / \mu \mathrm{L}$ (tibia). Sections were hybridized overnight at $53^{\circ} \mathrm{C}$. After hybridization, sections were washed with $50 \%$ formamide in $2 \times$ SSC at the hybridization temperature for 30 minutes and treated with RNase A (1 unit $/ \mathrm{mL}$ ) for 30 minutes at $37^{\circ} \mathrm{C}$. Subsequently, sections were rinsed in $2 \times$ SSC, treated with $1 \%$ blocking reagent for 30 minutes, and incubated with sheep antidigoxigenin $\mathrm{Fab}$ fragments conjugated with alkaline phosphatase $(1: 1,500)$ overnight at $4^{\circ} \mathrm{C}$.

Chromogenesis was performed in the dark with $0.38 \mathrm{mg} /$ $\mathrm{mL} \mathrm{NBT} \mathrm{and} 0.19 \mathrm{mg} / \mathrm{mL}$ BCIP in the presence of $6 \%(\mathrm{w} / \mathrm{v})$ polyvinyl alcohol [33], resulting in a blue precipitate. Finally, sections were counterstained with nuclear fast red, dehydrated through a series of ethanol, and mounted with Euparal. Sense probes were used to investigate the level of nonspecific binding.

\section{Quantification and Statistics}

First, a semiquantitative screening of all animals per group was performed on the antisense and sense slides to collect the in situ hybridization data. Sections I-V of all tibiae were scored in a semiquantitative manner, which was defined, on a Nikon Eclipse E800 microscope (Uvikon, Bunnik, The Netherlands), as follows: no expression (0), low expression (1), average expression (2), and high expression (3).

Effects of mechanical loading were expected in the shaft of the tibiae. Therefore, a second quantitative evaluation of the endocortical osteocytes expressing IGFBP-2 mRNA was performed with Lucia G Version 4.82 (Uvikon) using coded slides of sections II and III. The defined area of interest, which comprised the loading zone, started below the primary spongiosa at the endosteal side of the shaft following the total length of the shaft to the distal side (total length maximal 3,852 $\mu \mathrm{m})$. At the endosteal side of the shaft, all osteocytes, which were positioned within $100 \mu \mathrm{m}$ of the endosteal surface, were included in the area of interest. Within the area of interest, total osteocyte number and total IGFBP-2 mRNA-positive osteocyte number were measured.

The paired-samples Student's $t$-test and independent samples Student's $t$-test were used for statistical analysis using SPSS (Chicago, IL) version 9.0 for Windows. $P<0.05$ was considered to reflect statistical significance.

\section{Photography}

Brightfield photographs with different magnifications (objectives $\times 10, \times 20$, and $\times 40$ ) were made using a Leica microscope (DM4000B) with a digital camera (Leica DC500) and Leica software IM50 (Leica Microsystems, Rijswijk, The Netherlands).

\section{Results}

Endogenous IGFBP-2 mRNA Expression in Tissue

The control brain showed IGFBP-2 mRNA expression in the choroid plexus (Fig. 1A) and the neurons of the medulla oblongata (data not shown). In the internal control, i.e., the growth plate, IGFBP-2 mRNA was located in chondrocytes of the proliferative and hypertrophic zone (Fig. 1C). In control tibiae, IGFBP-2 mRNA was expressed in osteoblasts, which were situated against the surface of trabecular bone (Fig. 1C, E) and the endosteal side of the shaft (Fig. 1G). IGFBP-2 mRNA expression was also observed in some trabecular osteocytes and in cortical osteocytes, which were situated within the first lamella at the endosteal side of the shaft (Fig. 1G). The endocortical osteocytes, which were located within the deeper lamellae (Fig. 1G), and the periosteal osteocytes (Fig. 1D) did not express IGFBP-2 mRNA. IGFBP-2 mRNA was also expressed in the intracortical endothelial cells of blood vessels (Fig. 1G) and in the periosteum of control tibiae (Fig. 1D). Some cells of the bone marrow, i.e., megakaryocytes, macrophages, and myeloid cells, also expressed IGFBP-2 mRNA (Fig. 1E). No differences of IGFBP-2 mRNA expression between the right and left tibiae of the control group were observed using semiquantitative analysis.

Control hybridizations with the corresponding sense RNA probe exhibited no signals in the brain (Fig. 1B) and tibia (Fig. 1F).

Effect of Mechanical Loading on IGFBP-2 mRNA Expression in Osteocytes of the Tibial Shaft

Induced IGFBP-2 mRNA expression was observed in osteocytes within the first lamella and within multiple layers at the endosteal side of the shaft of loaded tibia (1.68-fold increase, $n=5$ ) (Fig. 1J) and sham-loaded tibia (1.35-fold increase, $n=5)($ Fig. $1 \mathrm{H})$ in contrast to the control tibia $(n=10)$, where IGFBP-2 mRNA expression was only seen within the first lamella of the endosteal side of the shaft (Fig. 1G).

The proportion of IGFBP-2 mRNA-positive osteocytes was $25.5 \pm 12.6 \%$ (mean \pm standard deviation [SD], $n=5$ ) for loaded tibiae and $17.2 \pm 10.7 \%$ (mean $\pm \mathrm{SD}, n=5$ ) for the contralateral control tibiae (Figs. 1G, J and 2A). Sham-loaded tibiae and the contralateral control tibiae showed a proportion of IGFBP-2 mRNA-positive osteocytes of $20.5 \pm 7.5 \%$ (mean $\pm \mathrm{SD}, n=5$ ) and $13.2 \pm 4.2 \%$ (mean $\pm \mathrm{SD}$, $n=5$ ), respectively (Figs. $1 \mathrm{H}$ and $2 \mathrm{~B}$ ). Mechanical loading significantly increased the number of IGFBP-2 mRNA-synthesizing osteocytes in loaded tibiae $(P=0.001)$ and in sham-loaded tibiae $(P=0.031)$ (Fig. 2A, B). No statistical differences of IGFBP-2 mRNA-positive osteocytes were observed between the contralateral controls of the loaded and sham-loaded tibiae $(P=0.475)$ or between the loaded and shamloaded tibiae $(P=0.468)$. 

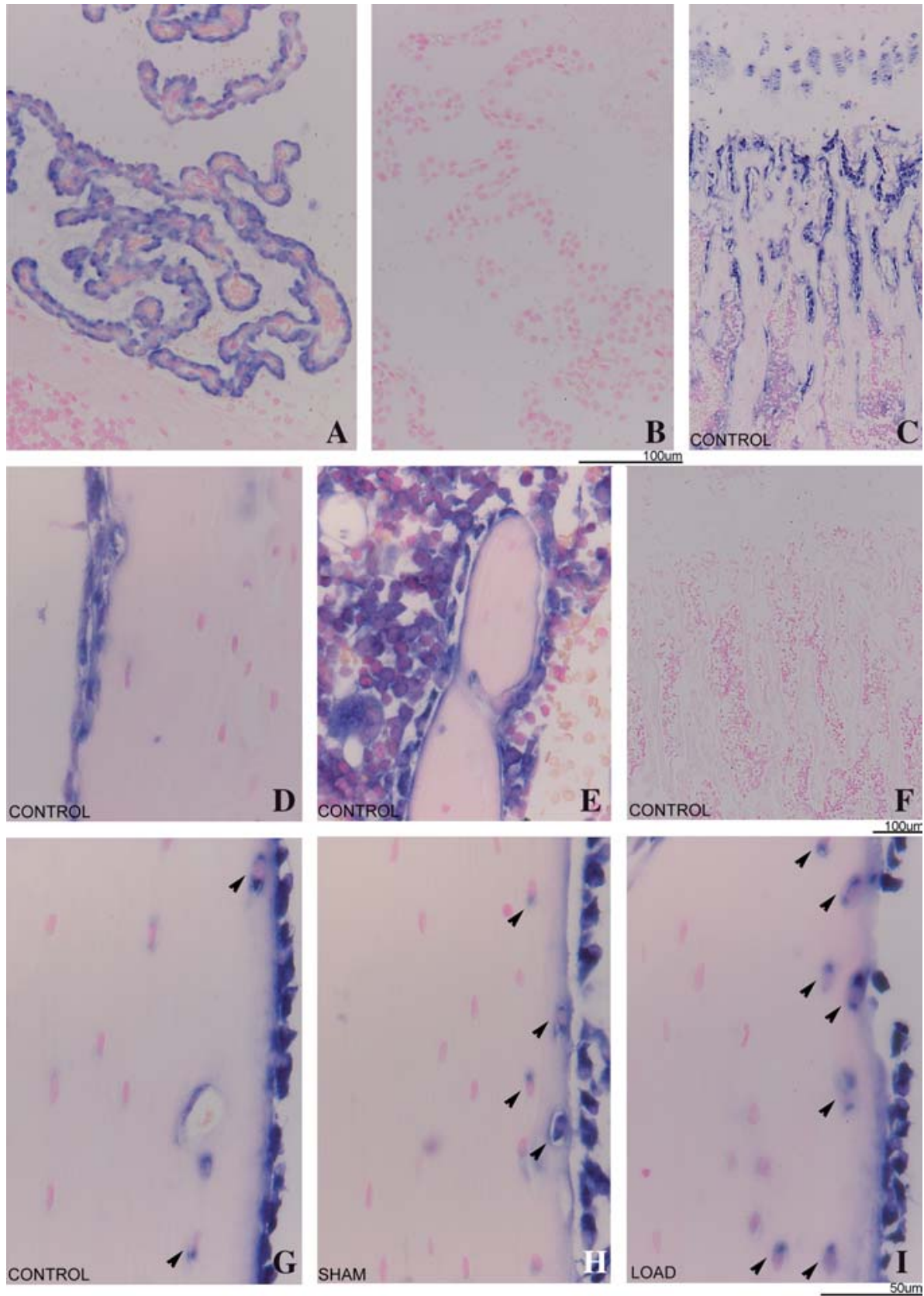

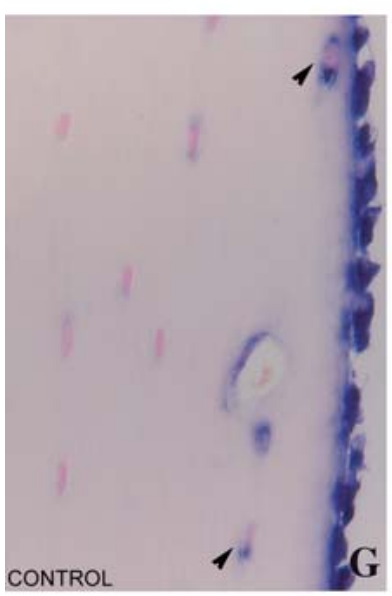

Fig. 1. Expression of IGFBP-2 mRNA in rat brain sections $(\mathbf{A}, \mathbf{B})$ and in longitudinal control $(\mathbf{C}-\mathbf{G})$, sham-loaded $(\mathbf{H})$, and loaded $(\mathbf{J})$ tibial sections of 12-week-old female Wistar rats. The RNA signal is shown as a blue precipitate. The sections were counterstained with nuclear fast red and visualized under brightfield illumination. The scale bars represent $100 \mu \mathrm{m}(\mathbf{A}, \mathbf{B}), 50 \mu \mathrm{m}(\mathbf{D}, \mathbf{E}, \mathbf{G}-\mathbf{J})$, and $100 \mu \mathrm{m}(\mathbf{C}, \mathbf{F})$. (A) IGFBP-2 mRNA expression within the choroid plexus of a control rat brain; red blood cells are negative and do not express IGFBP-2 mRNA. (B) Hybridization with representative IGFBP-2 sense probe showed no signal in the choroid plexus. (C) IGFBP-2 mRNA expression in the chondrocytes of the growth plate and osteoblasts of the trabecular bone. (D) IGFBP-2 mRNA expression in the periosteum of a control tibia; the osteocytes in the periosteal side of the shaft do not express IGFBP-2 mRNA. (E) IGFBP-2 mRNA expression in osteoblasts situated against the surface of normal trabecular bone and IGFBP-2-positive bone marrow cells. (F) Hybridization with a corresponding IGFBP-2 sense probe showed no signal in the osteoblasts, chondrocytes, and bone marrow cells of a control tibia. (G) IGFBP-2 mRNA expression within the superficial endocortical osteocytes (indicated by arrowheads), osteoblasts, and intracortical endothelial cells of a blood vessel of a control tibia. (H) IGFBP-2 mRNA expression in the endocortical osteocytes within multiple layers (indicated by arrowheads) and osteoblasts of a sham-loaded tibia. (J) IGFBP-2 mRNA expression in the endocortical osteocytes within multiple layers (indicated by arrowheads) and osteoblasts of a loaded tibia. 


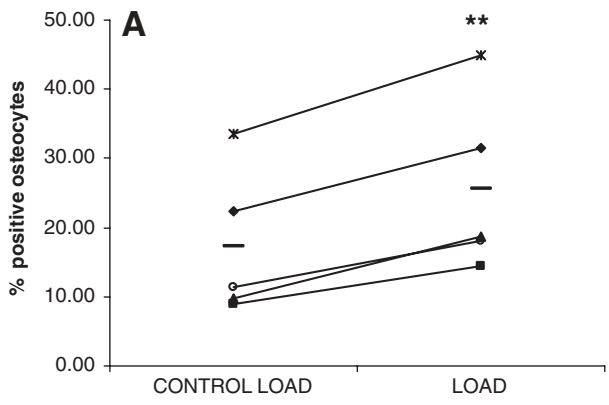

Fig. 2. Influence of mechanical loading on IGFBP-2 mRNA expression in osteocytes at the endosteal side of the shaft within individual rat tibiae. Values are expressed as (A) percentage IGFBP-2 mRNA-positive osteocytes in control versus contralateral loaded tibiae $\left({ }^{* *} P=0.001, n=5\right)$ and $(\mathbf{B})$ percentage IGFBP-2 mRNA positive osteocytes in control versus contralateral sham-loaded tibiae $\left({ }^{*} P=0.031, n=5\right)$. No

Effects of Mechanical Loading on IGFBP-2 mRNA Expression in Osteoblasts, Chondrocytes, and Bone Marrow Cells

No differences in IGFBP-2 mRNA expression between loaded, sham-loaded, and control tibiae were observed in the osteoblasts, chondrocytes, and bone marrow cells by semiquantitative screening. No differences in morphology of the cells were observed between groups.

\section{Discussion}

This in vivo study showed an increase in the number of endocortical osteocytes expressing IGFBP- 2 mRNA in loaded (1.68-fold) and sham-loaded (1.35-fold) tibiae 6 hours after a single period of mechanical loading with the four-point bending system. The upregulation of IGFBP-2 mRNA expression was restricted to osteocytes at the endosteal side of the shaft and multiple inner lamellae. No difference between IGFBP-2 mRNA expression in the left and right control tibia was observed. We conclude that bending and squeezing of rat tibiae result in an increase of locally synthesized IGFBP2 mRNA by endocortical osteocytes. We suggest that IGFBP-2 plays an as yet unidentified role in the lamellar bone formation process.

We suggest that the IGFBP-2-producing osteocytes of the loaded tibiae are involved in the increased lamellar bone formation after mechanical loading. Forwood and colleagues reported that a single short period of loading using the four-point bending system resulted in an increased lamellar bone formation rate at the endosteal surface of rat tibia [25]. This has been confirmed in a validation study at our laboratory [27]. The lamellar bone formation is located at the endosteal side of the shaft, which is identical to the location of newly synthesized IGFBP-2 mRNA after mechanical loading, as demonstrated in this study. IGFBP-2 mRNA expression was restricted to this area and was not ob- served in the osteocytes at the periosteal side of the shaft. Mechanical loading with an external bending load of $60 \mathrm{~N}$ in vivo will result in an increased woven bone formation rate at the periosteal surface as a result of irritation of the periosteum and increased lamellar bone formation rate at the endosteal surface [1]. We suggest that IGFBP-2 mRNA may be less involved in woven bone formation because the osteocytes at the periosteal side of the shaft did not express IGFBP-2. This suggests that IGFBP-2 mRNA in the mechanosensitive osteocytes is specifically important for lamellar bone formation.

In addition, this study showed that the sham-loaded tibiae have increased IGFBP-2 mRNA production in endocortical osteocytes 6 hours after sham loading. Apparently, besides bending, squeezing alone is also responsible for the upregulation of IGFBP- 2 mRNA in the endocortical osteocytes. However, squeezing did not induce lamellar bone formation.

Remarkably, there is a large range in the data for the percentage of IGFBP-2 mRNA-positive osteocytes in the contralateral control tibiae of the load group in comparison to the data of the contralateral tibiae of the sham group. This could be caused by the biological variation between the individuals because the animals were randomly divided between the groups and there is no significant statistical difference between those tibiae.

For this study we used the four-point bending model of Forwood because this apparatus produces a controlled mechanical strain in the tibia of living rats. An advantage of this approach is that it does not require surgical intervention and allows normal physical activity after the loading session [1,7]. The osteogenic response will occur at a distinct location in bone. Therefore, we used the in situ hybridization technique in order to detect the local osteogenic response at the cellular level. Nonradioactive in situ hybridization is a powerful and sensitive technique to localize gene expression within 
decalcified rat tibiae. It was demonstrated that the IGFBP-2 probe is specific because IGFBP-2 mRNA expression is present in the choroid plexus and the neurons of the medulla oblongata, as described earlier [28], and in the chondrocytes of the proliferative and hypertrophic zone of the growth plate [34].

Nevertheless, this study has some limitations. The applied load of $60 \mathrm{~N}$ is supraphysiological, and 6 hours after a single loading session is too early to demonstrate bone formation.

In summary, this study shows an increase of the number of osteocytes at the endosteal side of the shaft and inner lamellae expressing IGFBP-2 mRNA 6 hours after mechanical loading and sham loading in vivo. We conclude that these IGFBP-2-producing osteocytes in the endosteal shaft are mechanosensitive. We suggest that IGFBP-2 plays a role in the lamellar bone formation process.

Acknowledgement. The authors thank Huib van Essen (Department of Endocrinology, VU Medical University), Esther Lok, Suzanne Bonne, and Paula Mul (Clinical Laboratory for Animal Experiments) for assisting with the animal experiments.

\section{References}

1. Forwood MR, Bennett MB, Blowers AR, Nadorfi RL (1998) Modification of the in vivo four-point loading model for studying mechanically induced bone adaptation. Bone 23:307-310

2. Turner CH, Forwood MR, Rho JY, Yoshikawa T (1994) Mechanical loading thresholds for lamellar and woven bone formation. J Bone Miner Res 9:87-97

3. Yeh JK, Liu CC, Aloia JF (1993) Effects of exercise and immobilization on bone formation and resorption in young rats. Am J Physiol 264:E182-E189

4. Smith R, Rutherford OM (1993) Spine and total body bone mineral density and serum testosterone levels in male athletes. Eur J Appl Physiol Occup Physiol 67:330-334

5. Hamdy RC, Anderson JS, Whalen KE, Harvill LM (1994) Regional differences in bone density of young men involved in different exercises. Med Sci Sports Exerc 26:884-888

6. Forwood MR, Parker AW (1991) Repetitive loading, in vivo, of the tibiae and femora of rats: effects of repeated bouts of treadmill-running. Bone Miner 13:35-46

7. Turner $\mathrm{CH}$, Akhter MP, Raab DM, Kimmel DB, Recker RR (1991) A noninvasive, in vivo model for studying strain adaptive bone modeling. Bone 12:73-79

8. van der Wiel HE, Lips P, Graafmans WC, Danielsen CC, Nauta J, van Lingen A, Mosekilde L (1995) Additional weight-bearing during exercise is more important than duration of exercise for anabolic stimulus of bone: a study of running exercise in female rats. Bone 16:73-80

9. Torrance AG, Mosley JR, Suswillo RF, Lanyon LE (1994) Noninvasive loading of the rat ulna in vivo induces a strain-related modeling response uncomplicated by trauma or periostal pressure. Calcif Tissue Int $54: 241-247$

10. Frost HM (2003) Bone's mechanostat: a 2003 update. Anat Rec 275A:1081-1101

11. Martin RB, Burr DB (1989) Mechanical Adaptation: Structure, Function and Adaptation of Compact Bone. Raven Press, New York, 1989, chapters 2, 4, 7, and 8
12. Wang E, Wang J, Chin E, Zhou J, Bondy CA (1995) Cellular patterns of insulin-like growth factor system gene expression in murine chondrogenesis and osteogenesis. Endocrinology 136:2741-2751

13. Middleton J, Arnott N, Walsh S, Beresford J (1995) Osteoblasts and osteoclasts in adult human osteophyte tissue express the mRNAs for insulin-like growth factors I and II and the type 1 IGF receptor. Bone 16:287-293

14. Shinar DM, Endo N, Halperin D, Rodan GA, Weinreb M (1993) Differential expression of insulin-like growth factor-I (IGF-I) and IGF- II messenger ribonucleic acid in growing rat bone. Endocrinology 132:1158-1167

15. Lean JM, Jagger CJ, Chambers TJ, Chow JW (1995) Increased insulin-like growth factor I mRNA expression in rat osteocytes in response to mechanical stimulation. Am J Physiol 268:E318-E327

16. Raab-Cullen DM, Thiede MA, Petersen DN, Kimmel DB, Recker RR (1994) Mechanical loading stimulates rapid changes in periosteal gene expression. Calcif Tissue Int $55: 473-478$

17. Bravenboer N, Engelbregt MJ, Visser NA, Popp-Snijders C, Lips P (2001) The effect of exercise on systemic and bone concentrations of growth factors in rats. J Orthop Res 19:945-949

18. Conover C (1996) The role of insulin-like growth factors and binding proteins in bone cell biology. In: Principles of Bone Biology. Academic Press, San Diego, pp 607-618

19. Hassager C, Fitzpatrick LA, Spencer EM, Riggs BL, Conover CA (1992) Basal and regulated secretion of insulin-like growth factor binding proteins in osteoblastlike cells is cell line specific. J Clin Endocrinol Metab 75:228-233

20. Chen Y, Shu H, Ji C, Casinghino S, Kim K, Gundberg CM, Centrella M, McCarthy TL (1998) Insulin-like growth factor binding proteins localize to discrete cell culture compartments in periosteal and osteoblast cultures from fetal rat bone. J Cell Biochem 71:351-362

21. Palermo C, Manduca P, Gazzerro E, Foppiani L, Segat D, Barreca A (2004) Potentiating role of IGFBP-2 on IGF-IIstimulated alkaline phosphatase activity in differentiating osteoblasts. Am J Physiol Endocrinol Metab 286:E648E657

22. Canalis E (1997) Insulin-like growth factors and osteoporosis. Bone 21:215-216

23. Mohan S, Farley JR, Baylink DJ (1995) Age-related changes in IGFBP-4 and IGFBP-5 levels in human serum and bone: implications for bone loss with aging. Prog Growth Factor Res 6:465-473

24. Gabbitas B, Canalis E (1997) Growth factor regulation of insulin-like growth factor binding protein-6 expression in osteoblasts. J Cell Biochem 66:77-86

25. Forwood MR, Owan I, Takano Y, Turner CH (1996) Increased bone formation in rat tibiae after a single short period of dynamic loading in vivo. Am $\mathbf{J}$ Physiol 270:E419-E423

26. Akhter MP, Raab DM, Turner CH, Kimmel DB, Recker RR (1992) Characterization of in vivo strain in the rat tibia during external application of a four-point bending load. J Biomech 25:1241-1246

27. Tromp AM (2005) In vivo mechanical loading of the tibia, a pilot study in female rats. In: The Effects of Mechanical Loading and Estrogen on Bone Formation. PhD diss. Vrye Universiteit Amsterdam, pp 135-143

28. Reijnders CM, Koster JG, Buul-Offers SC (2004) Overexpression of human IGF-II mRNA in the brain of transgenic mice modulates IGFBP-2 gene expression in the medulla oblongata. J Endocrinol 182:445-455

29. Melton DA, Krieg PA, Rebagliati MR, Maniatis T, Zinn K, Green MR (1984) Efficient in vitro synthesis of biologically active RNA and RNA hybridization probes from plasmids containing a bacteriophage SP6 promoter. Nucleic Acids Res 12:7035-7056

30. Schuller AG, Zwarthoff EC, Drop SL (1993) Gene expression of the six insulin-like growth factor binding 
proteins in the mouse conceptus during mid- and late gestation. Endocrinology 132:2544-2550

31. Smink JJ, Koster JG, Hendriks-Stegeman BI, Buul-Offers SC van (1999) Insulin-like growth factor (IGF) II induced changes in expression of IGF binding proteins in lymphoid tissues of hIGF-II transgenic mice. Endocrinology 140:5876-5882

32. Wilkinson DG (1992) In Situ Hybridization: A Practical Approach. Oxford University Press, Oxford,
33. De Block M, Debrouwer D (1993) RNA-RNA in situ hybridization using digoxigenin-labeled probes: the use of high-molecular-weight polyvinyl alcohol in the alkaline phosphatase indoxyl-nitroblue tetrazolium reaction. Anal Biochem 215:86-89

34. Smink JJ, Koster JG, Gresnigt MG, Rooman R, Koedam JA, Buul-Offers SC (2002) IGF and IGF-binding protein expression in the growth plate of normal, dexamethasonetreated and human IGF-II transgenic mice. J Endocrinol $175: 143-153$ 